\title{
In vitro Drug Release Prediction of Hydrochlorothiazide Modified Release Tablet using Wagner Nelson Method and Deconvolution Approach:
}

\author{
Swapnil Sharma ${ }^{1}$, Sarvesh Paliwal ${ }^{1}$ and Vikas D Singhai ${ }^{2 *}$ \\ 1,2Department of Pharmacy, Banasthali Vidyapith, Banasthali, P.O. \\ Rajasthan-304022-India
}

\begin{abstract}
Background: Immediate release formulation of Hydrochlorothiazide is available in market. Cmax achieved at $2 \mathrm{~h}$, duration of action persist for 6-12 h, resulting in multiple dosing to maintain plasma concentration and in vivo activity. Objective: The objective of research work was to design modified release tablets of Hydrochlorothiazide $25 \mathrm{mg}$ with the intention of once a day dosing. Cmax will achieve after 10 to $12 \mathrm{~h}$ of administration. This controlled release will constantly induce diuretic activity for whole night and day especially during early morning hours, resulting in decreased blood volume, reduced cardiac output and controlled blood pressure. When patient awakes up in morning, blood pressure will be comparatively low thus reducing the frequency of cardiac arrest.Method: Here an attempt has been made to kinetically calculate required in-vitro dissolution profile by deconvolution method using Wagner-nelson equation. Plasma concentration time profile of immediate release tablet $12.5 \mathrm{mg}$ is available in literature and that of modified release formulation $25 \mathrm{mg}$ is calculated such that Area under curve of modified release tablet matches with that of two immediate release tablets of $12.5 \mathrm{mg}$ along with Cmax and Kel, thus meeting the criteria for bio-equivalency. Tmax will be delayed from $2 \mathrm{~h}$ to approximately $10 \mathrm{~h}$. Results: In-vivo dissolution profile is calculated from the equation of "fraction of drug absorbed". Perfect IVIVC is matched when value of slope is 1 , intercept is 0 and correlation coefficient $\left(R^{2}\right) 0.99$. Conclusion: This in-vitro profile will be used further to develop modified release formulation.
\end{abstract}

Keywords : Area under curve, Cmax, Elimination rate constant, Deconvolution, Wagner Nelson equation, IVIVC.

\section{Introduction}

\section{Heart Attack}

It is known for decades that the most dangerous time for all kind of cardiovascular emergencies including and not limited to heart attack, sudden cardiac death, failure in heart's electrical system rupture of the aorta, pulmonary embolism and stroke, are the early morning hours and during the last phase of sleep ${ }^{[1-4]}$.

Vikas D Singhai et al /International Journal of PharmTech Research, 2019,12(1): 49-56. 
Results from various studies suggest that most of the sudden deaths occur from 7 to 11 AM with lowest occurrence during sleep ${ }^{[5,6]}$. Cardiovascular system has oscillatory nature which follows a routine pattern it exhibit circadian changes. Imbalance between decreased myocardial oxygen supply (less oxygen available) and increased myocardial oxygen demand (more oxygen is needed in our heart) or sometimes both results in Heart attack. Physical activities of first hours of day starting from waking up require increased myocardial oxygen support. Adrenal hormone cortisol concentration increases in blood resulting increased blood - pressure along with elevated blood sugar levels. Further elevation of blood pressure and heart rate occurs due to catecholamines (adrenaline and noradrenaline), which are at their peak concentration when a person wake up in morning ${ }^{[7]}$.

\section{Hydrochlorothiazide}

Hydrochlorothiazide is most commonly prescribed anti-hypertensive and for more than three decades. The prescription pattern of HCTZ has been heavily influenced by the eight reports of Joint national committee for prevention, detection, evaluation and treatment of High blood pressure. All reports recommends "thiazide" or "thiazide-like drugs" or "thiazide type diuretics" as first line therapy with usual dose ranging from 12.5 to 50 mg per day in single or divided dose as recommended ${ }^{[8]} .2017$ guideline of Prevention, Detection, Evaluation, and Management of High Blood Pressure in Adults recommends HCTZas one of the primary agents to be used as oral antihypertensive drugs ${ }^{[9]}$. The more recent JNC reports have recommended that low dose thiazide and thiazide-like diuretics should be used as initial therapy in hypertensive patients.

HCTZ is available as immediate release tablet with multiple strengths (12.5mg to $100 \mathrm{mg}$ ). There are several combination also available of HCTZ immediate release tablet with antihypertensive drugs. Hydrochlorothiazide is rapidly absorbed from gastrointestinal tract. After oral administration onset of action occurs in $2 \mathrm{~h}$, peak effect is observed at approximately $4 \mathrm{~h}$. Duration of action persists for approximately 6 to $12 \mathrm{~h}$ after each dose $\mathrm{e}^{[10,11]}$ HCTZ belongs to BCS Class II molecule with poor water solubility and good permeability. For BCS Class I \& II molecules, permeability is high, hence fraction of drug dissolved (FRD) is equal to fraction of drug absorbed (FRA).

\section{IVIVC}

In-vitro In-vivo correlation is a mathematical relationship between in vitro properties of a dosage form with its in vivo performance. The in-vitro release data API serve as characteristic in vitro property, while the In vivo performance is generally represented by the time course of the plasma concentration of the active substance. Scientific treatment of these invitro and invivo data results in correlations. Dissolution rate is usually measured for solid oral dosage forms which characterize in vitro release. Linear and nonlinear mathematical correlation can be expressed to characterize in vitro and in vivo relationship. Direct correlation of plasma concentration with in vitro release cannot be done. Pharmacokinetic compartment model analysis or linear system analysis is used to convert plasma concentration to in vivo release or absorption data. ${ }^{[12]}$.

There are three levels of IVIVC which are defined: Level A which is considered most informative represents point to point relationship between in-vitro dissolution data and in-vivo plasma drug concentration time profile. It is also recommended by FDA. Level B IVIVC is not a point to point correlation and utilizes the principles of statistical moment theory where MDT (mean in-vitro dissolution time) is compared with MDT (mean in-vivo dissolution time) or MRT (mean in-vivo resident time). Level $\mathrm{C}$ is a single point correlation and compares one dissolution time point with one mean pharmacokinetic parameter such as $C_{\max }, T_{\max }$, AUC. This correlation is considered as the weakest among all as only a partial relationship is established.

Convolution is a combination of two mathematical functions to create third function.it is used to find out plasma drug concentration time profile from a unit input response and a given drug input rate. It can be performed by various available techniques including Laplace Transform technique, Analytical method or convolution by integral. Whereas Deconvolution is an exactly opposite mathematical procedure to convolution. Deconvolution method is used to determine in vivo drug dissolution using unique input response and plasma concentration time profile. This concept is very helpful in pharmacokinetics to determine drug input rates from available plasma drug profile. One of the methods to develop level A correlation is to estimate the in vivo absorption or dissolution time course using an appropriate deconvolution technique such as Wagnor - Nelson 
procedure, Loo-Riegelman method or numerical deconvolution. Wagner - Nelson is less complicated than Loo -Riegelman as there is no need of intravenous data, however both methods are model dependent ${ }^{[13]}$. According to Wagner-Nelson method, the cumulative fraction of drug absorbed at time $t$ is calculated from equation as follows.

$$
F_{T}=\frac{C_{T}+K_{E} \int_{0}^{T} C d t}{K_{E} \int_{0}^{\infty} C d t}
$$

Where $F_{T}$ is fraction of dose absorbed at time $t, C_{T}$ concentration of drug at time $t, K_{E}$ is elimination rate constant of drug, integration of concentration of drug from time ' 0 ' to ' $t$ ' is area under curve from time ' 0 ' to ' $t$ ' and integration of concentration of drug from time ' 0 ' to ' $\infty$ ' is area under curve from time ' 0 ' to 'infinity'.

\section{Experimental:}

\section{Calculation of AUC \& $\mathbf{C}_{\max }$ for Hydrochlorothiazide IR Tablets:}

The pharmacokinetic parameters of two oral formulations of 20/12.5 mg tablets of enalapril/ hydrochlorothiazide; Penopril as test and other commercially available preparation as reference were compared in an open-label randomized single oral dose two-period cross-over design to 24 healthy volunteers under fasting conditions. Pharmacokinetic parameters of $12.5 \mathrm{mg}$ hydrochlorothiazide were used from this study ${ }^{[14]}$. Similar data was observed in Hydrochlorothiazide $12.5 \mathrm{mg}$ tablet ${ }^{[15]}$. The results of two studies suggest that there is no major change in pharmacokinetics of hydrochlorothiazide $12.5 \mathrm{mg}$ when given alone or in combination. The mean pharmacokinetic parameters are compiled in Table 1.

Table 1: Mean pharmacokinetic parameters of hydrochlorothiazide $12.5 \mathrm{mg}$.

\begin{tabular}{|l|c|c|c|c|c|}
\hline & $\begin{array}{c}\mathbf{A U C}_{\mathbf{0}-\infty} \\
(\mathbf{n g} \mathbf{x} \mathbf{h} / \mathbf{m l})\end{array}$ & $\begin{array}{c}\mathbf{A U C} \mathbf{0 - \mathbf { t }} \\
(\mathbf{n g} \mathbf{x} \mathbf{h} / \mathbf{m l})\end{array}$ & $\begin{array}{c}\mathbf{C}_{\max } \\
(\mathbf{n g} / \mathbf{m l})\end{array}$ & $\begin{array}{c}\mathbf{T}_{\max } \\
(\mathbf{h})\end{array}$ & $\begin{array}{c}\mathbf{T}_{\mathbf{1} / \mathbf{2}} \\
(\mathbf{h})\end{array}$ \\
\hline $\mathrm{N}$ & 24 & 24 & 24 & 24 & 24 \\
\hline Geom. Mean & 566.0 & 516.2 & 81.4 & 1.8 & 5.0 \\
\hline Median & 574.4 & 516.5 & 82.4 & 2.0 & 4.9 \\
\hline Mean & 589.9 & 541.0 & 86.0 & 1.9 & 5.0 \\
\hline SD & 170.7 & 167.3 & 27.7 & 0.6 & 1.0 \\
\hline Min & 279.5 & 247.0 & 37.3 & 1.0 & 3.5 \\
\hline Max & 968.7 & 912.6 & 137.0 & 2.7 & 7.4 \\
\hline CV(\%) & 28.9 & 30.9 & 32.2 & 31.7 & 20.5 \\
\hline
\end{tabular}

Using this data Concentration of drug in $\mathrm{ng} / \mathrm{ml}$ for HCTZ $12.5 \mathrm{mg}$ single dose for $24 \mathrm{~h}$ was calculated. Values of concentration of drug at different time was found to be $0,56,77,67,58,48,37,33,23,21,17,15$, $12,9,8$ and $7 \mathrm{ng} / \mathrm{ml}$ for $0,1,2,3,4,5,6,7,8,9,10,11,12,16,20$ and $24 \mathrm{~h}$ respectively. From single dose study, pharmacokinetic parameters of two doses of hydrochlorothiazide $12.5 \mathrm{mg}$ dosed after every 12 his calculated. Concentration of drug up to $12 \mathrm{~h}$ will be same for $1^{\text {st }}$ IR dose as mentioned above. After $12 \mathrm{~h} 8$ $\mathrm{ng} / \mathrm{ml}$ concentration of drug is left. Hence this remaining concentration will be added to second dose (drug accumulation). Elimination phase after $20 \mathrm{~h}$ is kept similar to first dose. Values of Concentration of two doses of IR tablet at different time was found to be $0,56,77,67,58,48,37,33,23,21,17,15,12,68(56+12), 89$ (77+12), $79(67+12), 70(58+12), 60(48+12), 49(37+12), 45(33+12), 35(23+12), 21,17,15$ and $12 \mathrm{ng} / \mathrm{ml}$ for $0,1,2,3,4,5,6,7,8,9,10,11,12,13,14,15,16,17,18,90,20,21,22,23$ and 24 h respectively.

AUC is area under concentration time curve and is a measure of total systemic exposure of drug over time. It can be calculated from concentration - time data. AUC is not a primary pharmacokinetic parameter and is derived from clearance and dose. Area under curve is calculated using trapezoid method. This is also known as linear method and is most commonly used. Office of generic drugs at USFDA also prefers linear method. This method is used when concentration is increasing over time (absorption phase) and decreasing in polyexponential fashion. In this method area of each trapezoid is calculated and then summed to get AUC of curve.Followingformula is used to calculate AUC where ' $\mathrm{C}$ ' is the concentration of drug at two subsequent time 
point ' $\mathrm{T}$ '. Refer Table 2 for AUC calculation of Hydrochlorothiazide immediate release tablet $12.5 \mathrm{mg}$ single dose up to $24 \mathrm{~h}$.

Table 2: Area under curve (AUC) calculation of hydrochlorothiazide immediate release tablet $12.5 \mathrm{mg}$ single dose.

\begin{tabular}{|c|c|c|c|c|c|}
\hline $\begin{array}{c}\text { Time } \\
(\mathbf{h})\end{array}$ & $\begin{array}{c}\text { Concentration }- \\
\mathbf{1 2 . 5} \mathbf{~ m g} \\
(\mathbf{n g} / \mathbf{m l})\end{array}$ & $\begin{array}{c}\mathbf{C 1}+\mathbf{C 2} \\
(\mathbf{n g} / \mathbf{m l})\end{array}$ & $\begin{array}{c}\boldsymbol{\Delta} \mathbf{T} \\
(\mathbf{h})\end{array}$ & $\begin{array}{c}\text { AUC Linear } \\
(\mathbf{n g} \mathbf{x} \mathbf{h} / \mathbf{m l})\end{array}$ & $\begin{array}{c}\text { AUC Total } \\
(\mathbf{n g} \mathbf{x} \mathbf{h} / \mathbf{m l})\end{array}$ \\
\hline 0 & 0 & 0 & 0 & 0.00 & 0.00 \\
\hline 1 & 56 & 56 & 1 & 28.00 & 28.00 \\
\hline 2 & 77 & 133 & 1 & 66.50 & 94.50 \\
\hline 3 & 67 & 144 & 1 & 72.00 & 166.50 \\
\hline 4 & 58 & 125 & 1 & 62.50 & 229.00 \\
\hline 5 & 48 & 106 & 1 & 53.00 & 282.00 \\
\hline 6 & 37 & 85 & 1 & 42.50 & 324.50 \\
\hline 7 & 33 & 70 & 1 & 35.00 & 359.50 \\
\hline 8 & 23 & 56 & 1 & 28.00 & 387.50 \\
\hline 9 & 21 & 44 & 1 & 22.00 & 409.50 \\
\hline 10 & 17 & 38 & 1 & 19.00 & 428.50 \\
\hline 11 & 15 & 32 & 1 & 16.00 & 444.50 \\
\hline 12 & 12 & 27 & 1 & 13.50 & 458.00 \\
\hline 16 & 9 & 21 & 4 & 42.00 & 500.00 \\
\hline 20 & 8 & 17 & 4 & 34.00 & 534.00 \\
\hline 24 & 7 & 15 & 4 & 30.00 & $\mathbf{5 6 4 . 0 0}$ \\
\hline & & & & & \\
\hline
\end{tabular}

Area trapezoid

$$
\begin{array}{ll}
= & 1 / 2(\mathrm{C} 1+\mathrm{C} 2)(\mathrm{T} 2-\mathrm{T} 1) \\
= & 1 / 2(\mathrm{C} 1+\mathrm{C} 2) \Delta \mathrm{T}
\end{array}
$$

Total AUC was found to be 564.00. This is almost similar to AUC reported in literature ${ }^{[15]}$. AUC of two tablets of $12.5 \mathrm{mg}$ immediate release tablet can be doubled i.e. $564 \times 2=1128$. For modified release formulation of 25 mg once a day dose, AUC should lie within $80 \%$ to $125 \%$ of two immediate release formulation of $12.5 \mathrm{mg}$ which is 1128 i.e. 902 to 1410

\section{Calculation of AUC and in-vivo dissolution of HCTZ Modified Release tablets:}

Modified release formulation of HCTZ $25 \mathrm{mg}$ is prepared considering two doses of $12.5 \mathrm{mg}$ immediate release tablet. Hence in-vivo drug release profile for modified release tablet of $25 \mathrm{mg}$ HCTZ is predicted to match

1. AUC of 2 immediate release tablets of $12.5 \mathrm{mg}$ dosed at interval of $12 \mathrm{~h}$.

2. Elimination phase similar to immediate release tablets.

3. $\mathrm{C}_{\max }$ of modified release tablet is kept approximately $80-90 \%$ of immediate release tablet.

4. $\mathrm{C}_{\max }$ of modified release tablet is achieved after approx. $10 \mathrm{~h}$ of dosing. When tablet will be taken at evening, $C_{\max }$ will be achieved at around 4 to $5 \mathrm{am}$.

5. $\mathrm{T}_{\max }$ will be shifted from $2 \mathrm{~h}$ (IR tablet) to $10 \mathrm{~h}$ (MR tablet)

Along with AUC calculation, Fraction of dose absorbed is also calculated which is equal to in-vivo dissolution. Successive values of the right-hand side of Wagner - Nelson equation are calculated from the time of administration ( $\mathrm{t}=0$ ) to some-time after the peak in the blood level time plot (the area may be estimated by trapezoidal rule). The values progressively increased then reach a maximum or asymptotic value. When the individual values are expressed as percentage of the maximum values, the results are percent absorbed values to 
various time $\mathrm{T}^{[\mathbf{1 6 ]}}$. This is in-vivo drug dissolution. In-vivo dissolution calculation of modified release tablet 25 $\mathrm{mg}$ is shown in Table 3.

Table 3: Area under curve (AUC) and in vitro dissolution calculation of hydrochlorothiazide modified release tablet $25 \mathrm{mg}$.

\begin{tabular}{|c|c|c|c|c|c|c|c|c|}
\hline $\begin{array}{r}\text { Time } \\
\text { (h) }\end{array}$ & $\begin{array}{l}\text { Concentration } \\
\text { for } 12.5 \mathrm{mg} \\
(\mathrm{ng} / \mathrm{ml})\end{array}$ & $\begin{array}{c}\mathrm{C} 1+ \\
\mathrm{C} 2 \\
(\mathrm{ng} / \mathrm{ml})\end{array}$ & $\begin{array}{l}\Delta \mathrm{T} \\
(\mathbf{h})\end{array}$ & $\begin{array}{c}\text { AUC } \\
\text { Linear } \\
(\mathbf{n g ~ x} \\
\mathbf{h} / \mathbf{m l}) \\
\end{array}$ & $\begin{array}{l}\text { AUC } \\
\text { Total } \\
(\mathbf{n g ~ x} \\
\text { h/ml) } \\
\end{array}$ & $\begin{array}{l}\text { AUC } \\
\text { X Kel }\end{array}$ & $\begin{array}{c}\text { Conc }+ \\
(\text { AUC x } \\
\text { Kel) }\end{array}$ & $\begin{array}{c}\text { In vivo } \\
\text { Dissolution } \\
(\%)\end{array}$ \\
\hline 0 & 0 & 0 & 0.00 & 0.00 & 0.00 & 0.00 & 0.00 & 0 \\
\hline 1 & 18 & 18 & 1.00 & 9.00 & 9.00 & 0.68 & 18.68 & 16 \\
\hline 2 & 30 & 48 & 1.00 & 24.00 & 33.00 & 2.51 & 32.51 & 28 \\
\hline 3 & 39 & 69 & 1.00 & 34.50 & 67.50 & 5.13 & 44.13 & 37 \\
\hline 4 & 45 & 84 & 1.00 & 42.00 & 109.50 & 8.32 & 53.32 & 45 \\
\hline 5 & 51 & 96 & 1.00 & 48.00 & 157.50 & 11.97 & 62.97 & 53 \\
\hline 6 & 56 & 107 & 1.00 & 53.50 & 211.00 & 16.04 & 72.04 & 61 \\
\hline 7 & 60 & 116 & 1.00 & 58.00 & 269.00 & 20.44 & 80.44 & 68 \\
\hline 8 & 62 & 122 & 1.00 & 61.00 & 330.00 & 25.08 & 87.08 & 74 \\
\hline 9 & 64 & 126 & 1.00 & 63.00 & 393.00 & 29.87 & 93.87 & 80 \\
\hline 10 & 66 & 130 & 1.00 & 65.00 & 458.00 & 34.81 & 100.81 & 85 \\
\hline 11 & 66 & 132 & 1.00 & 66.00 & 524.00 & 39.82 & 105.82 & 90 \\
\hline 12 & 66 & 132 & 1.00 & 66.00 & 590.00 & 44.84 & 110.84 & 94 \\
\hline 13 & 65 & 131 & 1.00 & 65.50 & 655.50 & 49.82 & 114.82 & 97 \\
\hline 14 & 64 & 129 & 1.00 & 64.50 & 720.00 & 54.72 & 118.72 & 101 \\
\hline 15 & 63 & 127 & 1.00 & 63.50 & 783.50 & 59.55 & 122.55 & 104 \\
\hline 16 & 60 & 123 & 1.00 & 61.50 & 845.00 & 64.22 & 124.22 & 105 \\
\hline 17 & 55 & 115 & 1.00 & 57.50 & 902.50 & 68.59 & 123.59 & 105 \\
\hline 18 & 49 & 104 & 1.00 & 52.00 & 954.50 & 72.54 & 121.54 & 103 \\
\hline 19 & 45 & 94 & 1.00 & 47.00 & 1001.50 & 76.11 & 121.11 & 103 \\
\hline 20 & 35 & 80 & 1.00 & 40.00 & 1041.50 & 79.15 & 114.15 & 97 \\
\hline 21 & 21 & 56 & 1.00 & 28.00 & 1069.50 & 81.28 & 102.28 & 87 \\
\hline 22 & 17 & 38 & 1.00 & 19.00 & 1088.50 & 82.73 & 99.73 & 85 \\
\hline 23 & 15 & 32 & 1.00 & 16.00 & 1104.50 & 83.94 & 98.94 & 84 \\
\hline \multirow[t]{2}{*}{24} & 12 & 27 & 1.00 & 13.50 & 1118.00 & 84.97 & 96.97 & 82 \\
\hline & & & & 1118.00 & & & & \\
\hline
\end{tabular}

The elimination rate constant (Kel) can be obtained from the least-square fitted terminal log-linear portion of the plasma concentration - time profile. Value of Elimination rate constant is available in various literatures and ranging from 0.070 to $0.077^{[17-20]}$. For this calculation value of Kel used is 0.076 . For In-vivo dissolution, asymptotic values of AUC x Ke are calculated from $11 \mathrm{~h}$ to $20 \mathrm{~h}$. The average value found to be 118.

\section{Result \& Discussion}

Area under curve of modified release tablet of $25 \mathrm{mg}$ single dose is calculated as 1037 . This is almost similar to AUC of 2 immediate release tablets which is $1128 . \mathrm{C}_{\max }$ of Modified release tablet $(66 \mathrm{ng} / \mathrm{ml})$ lies between $80-90 \%$ of immediate release tablet $(77 \mathrm{ng} / \mathrm{ml})$. Elimination rate of both formulation is also same. Target plasma drug concentration profile on two immediate release tablet of $12.5 \mathrm{mg}$ and one modified release tablet of $25 \mathrm{mg}$ is shown in Figure 1 


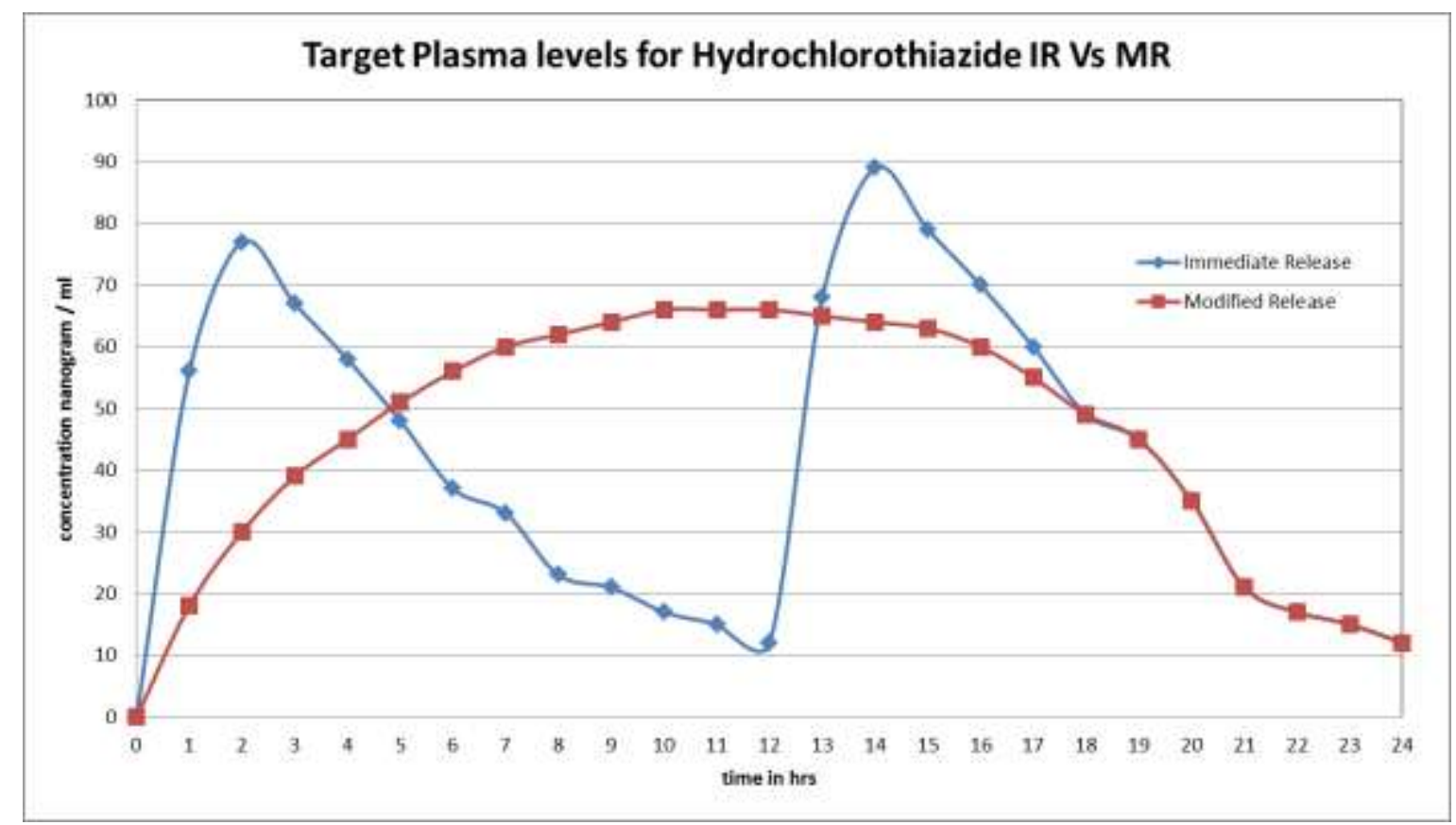

Figure 1: In vivo Plasma Drug concentration of Immediate Release Vs Modified Release for Hydrochlorothiazide

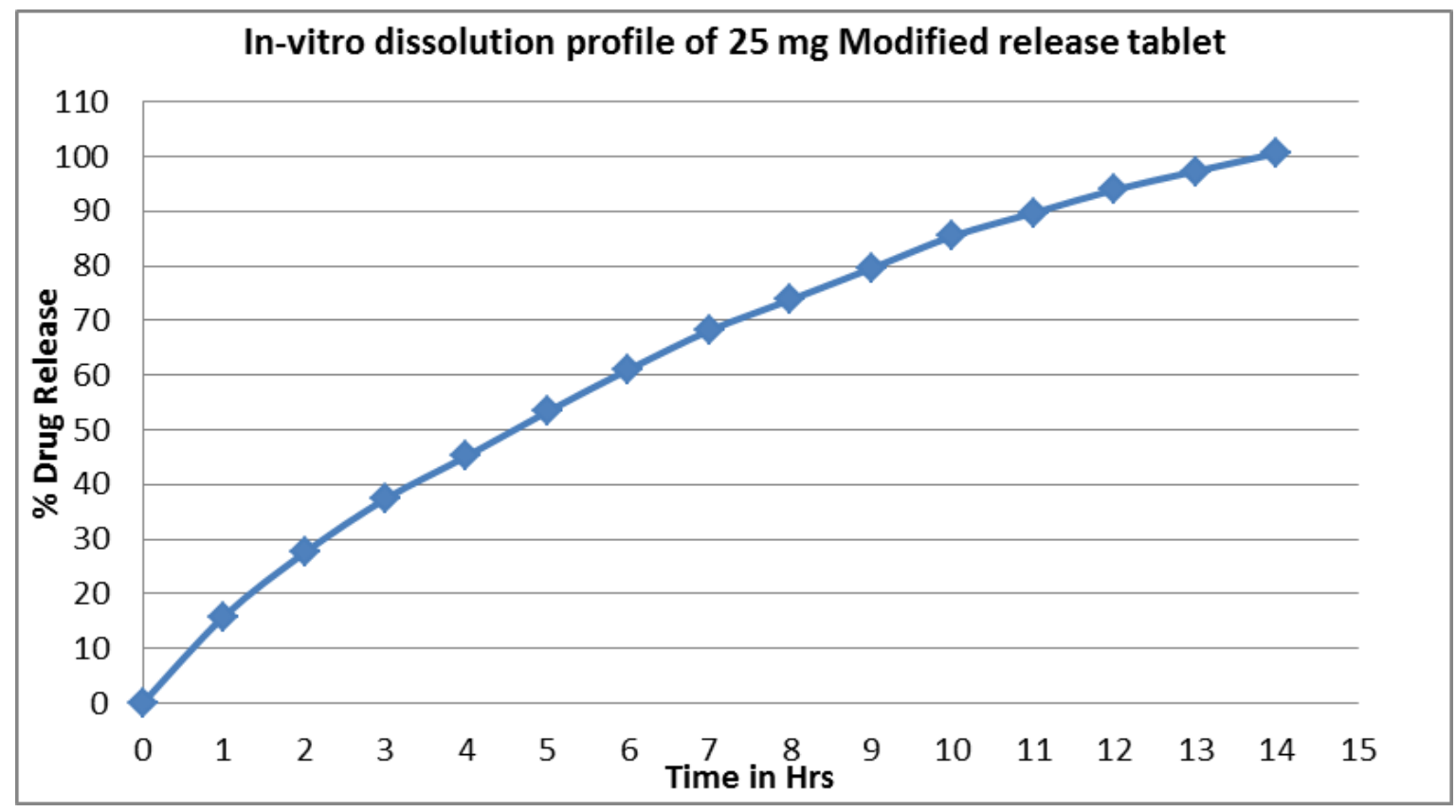

Figure 2: Required In vitro Dissolution profile for Hydrochlorothiazide 25 mg Modified Release Tablet

To match level A of IVIVC, point to point correlation is required. Perfect correlation is only achieved when value of slope of 1 , intercept is 0 and $\mathrm{R}^{2}$ value is 0.99 by comparing in-vivo and in-vitro dissolution. Thus required in-vitro dissolution profile is same as of calculated in-vivo dissolution. Target In-vitro dissolution to be achieved for formulation development is $0,16,28,37,45,53,61,68,74,80,85,90,94,97$ and $100 \%$ of drug release at $0,1,2,3,4,5,6,7,8,9,10,11,12,13$ and $14 \mathrm{~h}$ respectively. In-vitro drug release Vs time plot is shown in Figure 2. 


\section{Conclusion:}

Required in-vitro dissolution profile was predicted for hydrochlorothiazide modified release tablet 25 mg using Wagner-Nelson equation and deconvolution based approach. Criteria to match bio equivalence for two formulation is fulfilled i.e. AUC and $\mathrm{C}_{\max }$. Next step is the formulation and development of modified release tablet of hydrochlorothiazide. The similar and consistent PK/PD outcomes can be anticipated in human volunteers when tablets manufactured complying calculated dissolution profile is prepared and in-vivo study performed. This modified release tablet of Hydrochlorothiazide can be given alone or in combination with any of the beta blockers or other antihypertensive drugs as prescribed by physician. The synergistic effect will enhance pharmacological action of both drugs.

\section{Abbreviations}

JNC: joint national committee; BCS: biopharmaceutical classification system of drug; FRD: fraction of drug dissolved; FRA: fraction of drug absorbed; IVIVC: in-vitro in-vivo correlation; AUC: area under curve; Cmax: maximum concentration of drug; Tmax: time to reach maximum concentration; IR: immediate release; HCTZ: hydrochlorothiazide; $\mathrm{T}_{1 / 2}$ : half-life of drug; Conc: concentration; Kel: elimination rate constant; PK: pharmacokinetic; PD: pharmacodynamics; USFDA: united states food and drug administration; API: active pharmaceutical ingredient.

\section{References:}

1. Wroe SJ, Sandercock P, Bamford J, Dennis M, Slattery J, Warlow C. Diurnal variation in incidence of stoke: Oxfordshire community stroke project, British Medical Journal, 1992; 304: 155-7. doi:10.1136/bmj.304.6820.155.

2. Tofler GH, Brezinski D, Schafer AI, Czeisler CA, Rutherford JD, Willich SN et al. Concurrent morning increase in platelet aggregability and the risk of myocardial infraction and sudden cardiac death,The New England Journal of Medicine,1987; $316: 1514$ - 8 . doi:10.1056/NEJM198706113162405.

3. Wolk R, Gami AS, Garcia-Touchard A, Somers VK. Sleep and Cardiovascular disease,Current Problems in Cardiology, 2005;30: 625-62. doi:10.1016/j.cpcardiol.2005.07.002.

4. Lampert R, Rosenfeld L, Batsford W, Lee F, McPherson C. Circadian Variation of Sustained Ventricular Tachycardia in patients with coronary artery disease and implantable cardioverter defibrillators,Circulation,1994; 90: 241-7. doi:10.1161/01.CIR.90.1.241.

5. Guo YF, Stein PK. Circadian rhythm in the cardiovascular system:chronocardiology,American Heart Journal, 2003; 145: 779-86. doi:10.1016/S0002-8703(02)94797-6.

6. Andreotti F, Davies GJ, Hackett DR, Khan MI, De Bart AC, Aber VR et al. Major circadian fluctuations in fibrinolytic factors and possible relevance to time of onset of mycocardial infraction, sudden cardiac death and stroke,AmericanJournal of Cardiology,1988; 62: 635-7. doi:10.1016/00029149(88)90669-8.

7. Willich SN, Levy D, Rocco MB, Tofler GH, Stone PH, Muller JE. Circadian variation in the incidence of sudden cardiac death in the Framingham Heart Study Population, American Journal of Cardiology, 1987; 60: 801-6. doi:10.1016/0002-9149(87)91027-7.

8. The seventh report of the joint national committee on Prevention, Detection, Evaluation and Treatment of high blood pressure. U.S. Department of health and human services. August 2004.

9. 2017 Guideline for the Prevention, Detection, Evaluation, and Management of High Blood Pressure in Adults. A report of the American College of Cardiology/American Heart Association Task Force on Clinical Practice Guidelines.

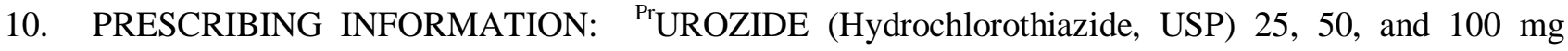
Tablets; Date of revision: January 16, 2013.

11. PRODUCT MONOGRAPH: ${ }^{\text {PR }}$ APO-HYDRO Hydrochlorothiazide Tablets USP $12.5 \mathrm{mg}$; Date of revision: April 4, 2014.

12. Sakore S, Chakraborty B. In Vitro-In Vivo Correlation (IVIVC): A Strategic Tool in Drug Development, Journal of bioequivalence \& bioavailability, 2011; S3: 1-12.

13. Gibaldi, M, Perrier D. Pharmacokinetics. $2^{\text {nd }}$ ed. Marcel Dekker: New York 1982. 
14. Niopas I, Daftsios AC, Nikolaidis N. Evaluation of the Bioequivalence of Two Tablet Formulations of Enalapril/Hydrochlorothiazide after Single Oral Administration to Healthy Volunteers, ArzneimittelForschung,2004; 54: 160-5.

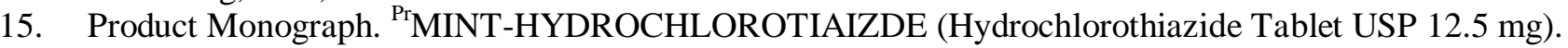

16. Wagner JG, Nelson E. Percent absorbed time plots derived from blood level and/orurinary excretion data, Journal of Pharmaceutical Sciences, 1963; 52: 610-1.

17. Shah JV, Parekh JM, Shah PA, Shah PV, Sanyal M, Shrivastav PS. Application of an LC-MS/MS method for the analysis of amlodipine, valsartan and hydrochlorothiazide in polypill for a bioequivalence study,Journal of Pharmaceutical and Biomedical Analysis,2017; 7: 309-16. doi:10.1016/j.jpha.2017.06.001.

18. Public Assessment report; Scientific Discussion. Omlesartan medoxomil / hydrochlorothiazide "Krka". DK/H/2521/001-004/DC. 27 March 2017

19. European Medicines Agency; CHMP assessment report. Ifirmacombi (Irbesartan / hydrochloeo thiazide). Procedure No. EMEA/H/C/002302

20. Public Assessment Report; Scientific discussion. Tevaltan comp (Valsartan and hydrochlorothiazide) DK/H/1524/001-002/DC. 